\title{
Sensitivity of precipitation forecasts to convective parameterization in the October 2007 Flash Flood in the Valencia Region (Eastern Spain)
}

\author{
I. Gómez ${ }^{1}$, F. Pastor ${ }^{1}$, and M. Estrela ${ }^{2}$ \\ ${ }^{1}$ Laboratorio de Meteorología-Climatología, Unidad Mixta CEAM-UVEG, Fundación Centro de Estudios Ambientales del \\ Mediterráneo, Programa de Meteorología y Climatología, Paterna (Valencia), Spain \\ ${ }^{2}$ Laboratorio de Meteorología-Climatología, Unidad Mixta CEAM-UVEG, Departament de Geografia Física, Universitat de \\ València, Valencia, Spain
}

Received: 21 January 2010 - Revised: 5 March 2010 - Accepted: 24 March 2010 - Published: 30 June 2010

\begin{abstract}
The Valencia region, on the Mediterranean coast of the Iberian Peninsula, is an area prone to torrential rains, especially the north of Alicante province and the south of Valencia province. In October 2007, a torrential rain event with accumulated rainfall values exceeding $400 \mathrm{~mm}$ in less than $24 \mathrm{~h}$ affected the aforementioned areas, producing flash floods that caused extensive economic losses and human casualties. Several simulations of this rain event have been performed with the Regional Atmospheric Modeling System (RAMS) to test the influence of the different convective parameterization scheme implemented in the model on the precipitation forecast.
\end{abstract}

\section{Introduction}

Torrential rains and flash-floods are common in the Western Mediterranean, occurring mostly from late summer to autumn. These heavy rain events can cause high economic losses and, sometimes, human casualties. Thus, a better understanding and a proper forecasting of these events is an important issue in Mediterranean meteorology. Numerous efforts addressing this problem from different points of view have been made during recent years, ranging from the study of trends in both the number of torrential events and their precipitation (Alpert et al., 2002; Peñarrocha et al., 2002; Millán et al., 2005) to the study of the favourable atmospheric envi-

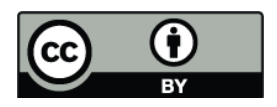

Correspondence to: I. Gómez

(igor@ceam.es) ronment for heavy rains in the Mediterranean basin (Millán et al., 1995; Estrela et al., 2002, 2003; Fita et al., 2007). Numerous efforts have also been devoted to different aspects and sensitivities of the numerical modelling of such torrential rain events (Bresson et al., 2009; Federico et al., 2008, Pastor et al., 2001; Lebeaupin et al., 2006, 2009; Miglietta and Regano, 2008).

In October 2007 a torrential rain event took place in the Valencia region, mainly affecting coastal areas and nearby mountains in the center-south of the region. More than $400 \mathrm{~mm}$ in $24 \mathrm{~h}$ were recorded at some stations in this area, with less intense rainfall in the rest of the region. A detailed description of this rain event, from its meteorological scenario and recorded data to its numerical modelling using Regional Atmospheric Modeling System (RAMS) (Pielke et al., 1992; Cotton et al., 2003), is given in Pastor et al. (2010).

In the present work, the authors investigate the effects of the different convective parameterization schemes implemented in RAMS model on precipitation forecasts. This is done by means of high-resolution simulations of the October 2007 rain event.

\section{Model configuration}

Six different sensitivity experiments have been carried out with RAMS in its version 6.0. These simulations have been performed using two-way interactive nested grids at increasing horizontal resolution of $40.5,13.5,4.5$ and $1.5 \mathrm{~km}$, respectively. Vertical discretization consists of a 45-level stretched vertical coordinate with a $30 \mathrm{~m}$ spacing near the

Published by Copernicus Publications on behalf of the European Geosciences Union. 

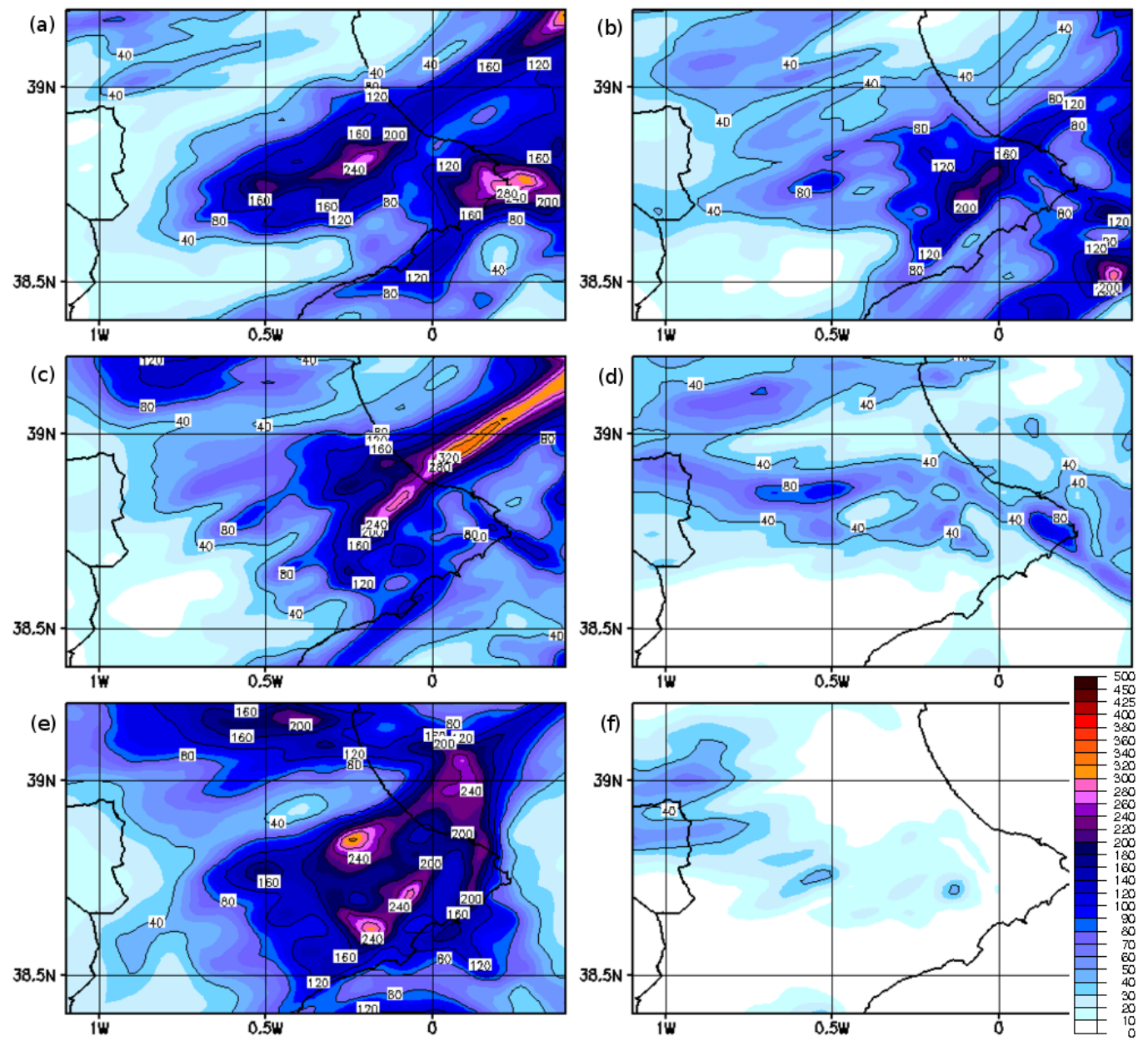

Fig. 1. RAMS forecast accumulated precipitation for the whole event: (a) Kuo1, (b) KF1, (c) Kuo2, (d) KF2, (e) Kuo3 and (f) KF3 (mm).

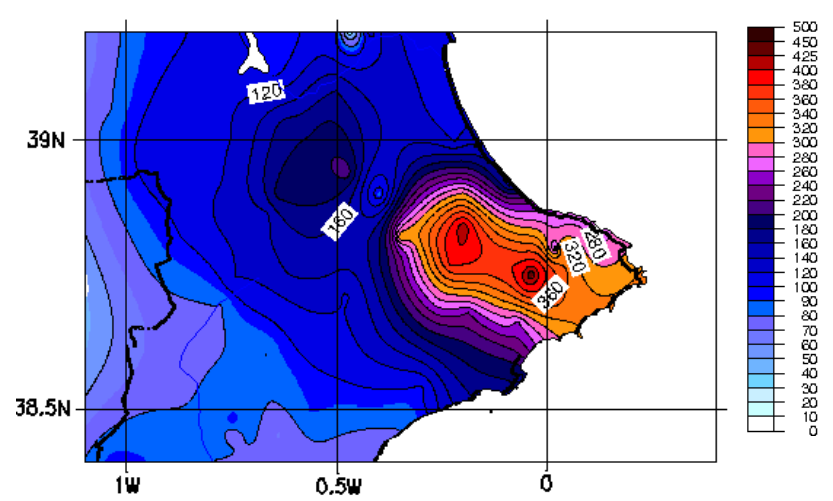

Fig. 2. Accumulated precipitation ( $\mathrm{mm}$ ) observed for the $48 \mathrm{~h}$ period 11-12 October 2007. Data recorded by CEAM Meteorology Department, Spanish Meteorological Agency (AEMET) and Confederación Hidrográfica del Júcar (CHJ). surface increasing gradually up to $1000 \mathrm{~m}$ near the model top at $16000 \mathrm{~m}$. The atmospheric boundary and initial conditions are obtained from the National Centre for Environmental Prediction (NCEP) global Final Analyses (FNL), available every $6 \mathrm{~h}$ at $1 \times 1$ degree resolution. Simulations of $48 \mathrm{~h}$ are run for each experiment, starting at 00:00 UTC on $11 \mathrm{Oc}-$ tober 2007. The convective parameterization schemes supplied by RAMS are activated/deactivated in the three outer domains: Kuo (Molinari, 1985) and Kain-Fritsch (KF) (Kain and Fritsch, 1993; Castro et al., 2002) schemes (Table 1). Convection is explicitly resolved in the inner domain.

\section{Results}

The effect of activating or not activating a convective parameterization scheme in the three outer grids is investigated by considering the total accumulated precipitation and its hourly evolution against observations for each of the experiments. The results are analysed only for the inner model domain, which is centred on the rain area. From this analysis, it has 


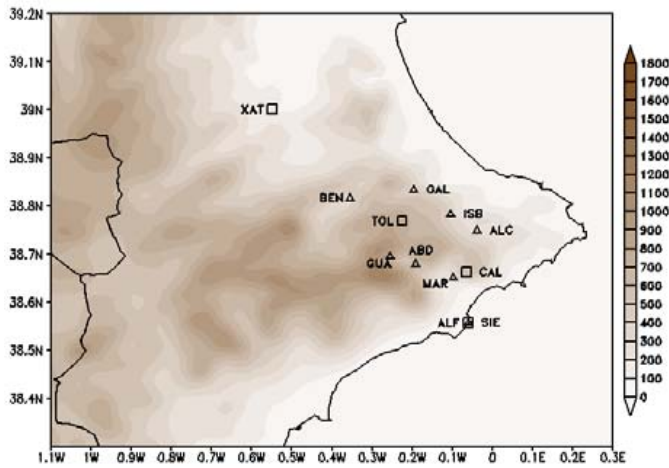

(a)

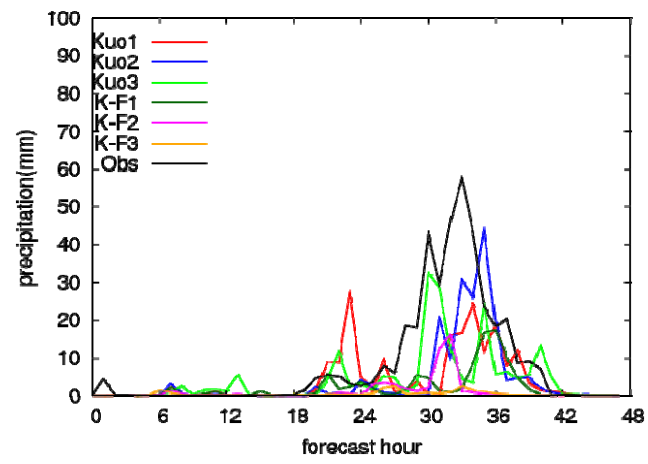

(c)

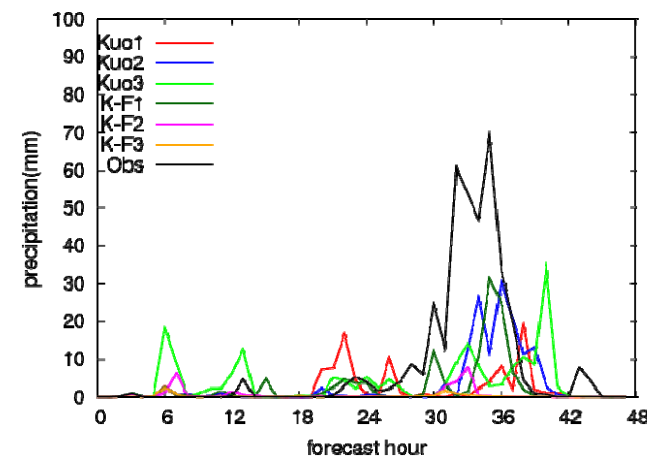

(b)

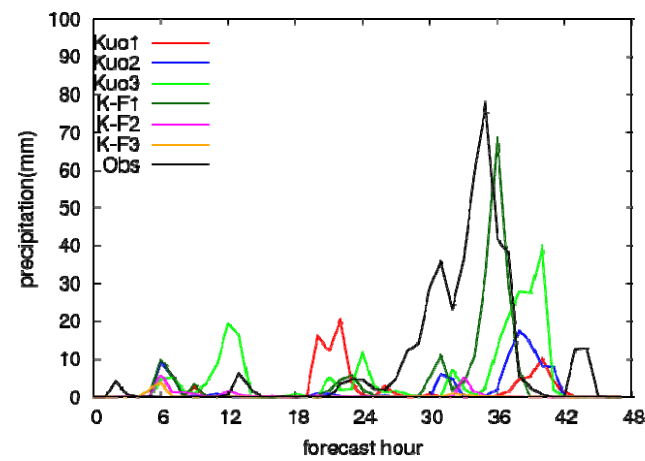

(d)

Fig. 3. (a) Grid 4 topography with stations in the area of maximum rainfall. Time evolution of observed and forecast precipitation (whole simulation time) at (b) Isbert (ISB) (c) Tollos (TOL) and (d) Alcalalí (ALC).

Table 1. Sensitivity experiments. Cumulus scheme settings (no cumulus parameterization on Grid 4).

\begin{tabular}{lccc}
\hline Experiment & Grid 1 & Grid 2 & Grid 3 \\
\hline Kuo1 & Kuo & N/A & N/A \\
Kuo2 & Kuo & Kuo & N/A \\
Kuo3 & Kuo & Kuo & Kuo \\
KF1 & KF & N/A & N/A \\
KF2 & KF & KF & N/A \\
KF3 & KF & KF & KF \\
\hline
\end{tabular}

become clear that convective parameterization has a significant impact on the precipitation forecast in RAMS model.

\subsection{Accumulated precipitation and spatial location}

Forecast accumulated precipitation for the six different simulations are shown in Fig. 1. It can be seen that Kuo1 produces two precipitation maxima in the target area, capturing the location and underestimating the amount of rainfall observed (Fig. 2). Kuo2 displays only a narrow area of precipitation.
Although in both cases, precipitation values exceed $250 \mathrm{~mm}$, in terms of "integrated rainfall" over the target area, Kuo1 is remarkable better than Kuo2. The best results for the Kuo scheme experiments are obtained when the Kuo convective parameterization is activated in the three outer grids of the simulation. Then, the spatial distribution of the precipitation correctly fits the actual recorded precipitation in both extension and location. But, again, precipitation values are underpredicted although Kuo3 yields maximum accumulated values above $270 \mathrm{~mm}$, and a broad area over $100 \mathrm{~mm}$. In all three experiments the rain area extends from south-west to north-east and out over the sea.

In the case of the Kain-Fritsch convective parameterization scheme experiments, only KF1 gives good results while KF2 and KF3 show very low accumulated precipitation values. In KF1 the high precipitation area is less extensive than the real one, but it is well located. As in the Kuo experiments, the KF1 maximum precipitation value of $180 \mathrm{~mm}$ is underestimated with respect to the observed values. The other two experiments, KF2 and KF3, show very low values, below 90 and $50 \mathrm{~mm}$ respectively, and the location is moved to the north and inland. 


\subsection{Time evolution}

Three stations representative of the general evolution of the forecast precipitation in the area of maximum rainfall for the whole event are analysed in this section. The comparison of the hourly evolution of the observed and forecast precipitation at these stations is shown in Fig. 3. During the first 20 hours of the simulation, very little or no precipitation was recorded. At most stations, the Kain-Fritsch, Kuo1 and Kuo2 experiments produce almost no precipitation while the Kuo3 experiment shows some precipitation peaks that are not observed. The heavy rainfall started between 20 and $24 \mathrm{~h}$ from the beginning of the simulation. Within this 4-h period, Kuol produces a rainfall that was not actually observed. The hourly evolution of the precipitation is not well reproduced for the Kuo3 experiment and for the whole simulation period. Moreover, precipitation is strongly under-predicted for the Kuo2 experiment. In contrast, KF1 produces better results than the other KF experiments. In fact, KF1 results are in general similar to those using the Kuo scheme, especially Kuo2 and Kuo3, with the maximum precipitation peaks captured even better for some stations, as for example, Alcalalí (Fig. 3d).

\section{Conclusions}

Several numerical simulations of an extraordinary rain event have been run. In each simulation, the implementation of convective parameterization schemes has been modified in order to investigate the effect on the precipitation forecasts. The two convective parameterization schemes in the RAMS model (Kuo and Kain-Fritsch) have been used on different domains with different spatial resolution. The methodology followed consisted of running different high-resolution simulations with four nested grids, activating or deactivating the parameterization schemes in different combinations of the three outer grids for each simulation.

To summarize the results: KF1 seems to better capture the precipitation maximum intensity peaks despite its poor achievement in accumulated totals. Although Kuo3 shows the best performance in both the location and the total accumulation of the precipitation, its hourly distribution performance is worse than KF1 and Kuo2. In general, the Kuo scheme experiments reproduce the precipitation event well, although with a remarkable underestimation (about $50 \%$ lower than observation). For most stations, the best results in event duration and peaks are produced by Kuo 2 and Kuo3 experiments, while in Kuo1 the precipitation starts too soon and does not reproduce enough precipitation intensities during the rainfall.
Acknowledgements. This work has been funded by the Spanish Ministerio de Educación y Ciencia through the projects CGL200804550 (Proyecto NIEVA), CSD2007-00067 CONSOLIDERINGENIO 2010 (Proyecto GRACCIE) and CGL2007-65774/CLI (Proyecto MAPSAT) and by the EU-funded Integrated Project CIRCE (Proj. No. 036961). Fundación CEAM is supported by the Generalitat Valenciana and BANCAIXA. The authors wish to thank NCEP for providing the meteorological analysis for RAMS initialization. FNL data are from the Research Data Archive (RDA) which is maintained by the Computational and Information Systems Laboratory (CISL) at the National Center for Atmospheric Research (NCAR). We also want to thank Jackie Scheiding for the review of the English text.

Edited by: A. Mugnai

Reviewed by: one anonymous referee

\section{References}

Alpert, P., Ben-Gai, T., Baharad, A., Benjamini, Y., Yekutieli, D., Colacino, M., Diodato, L., Ramis, C., Homar, V., Romero, R., Michaelides, S., and Manes, A.: The paradoxical increase of Mediterranean extreme daily rainfall in spite of decrease in total values, Geophys. Res. Lett., 29(11), 31-1/31-4, doi:10.1029/2001GL013554, 2002.

Bresson, R., Ricard, D., and Ducrocq, V.: Idealized mesoscale numerical study of Mediterranean heavy precipitating convective systems, Meteorol. Atmos. Phys., 103, 45-55, doi:10.1007/s00703-008-0338-z, 2009.

Castro, C. L., Cheng, W. Y. Beltrán , Y., A. B., Marshall Jr., C. H., Pielke, R. A., and Cotton, W. R.. The incorporation of the Kain-Fritsch cumulus parameterization scheme in RAMS with a terrain-adjusted trigger function. Fifth RAMS Users and Related Applications Workshop, Santorini. Greece, 2002.

Cotton, W. R., Pielke, R. A., Walko, R. L., Liston, G. E., Tremback, C. J., Jiang, H., McAnelly, R. L., Harrington, J. Y., Nicholls, M. E., Carrio, G. G., and McFadden, J. P.: RAMS 2001: Current status and future directions, Meteorol. Atmos. Phys., 82, 5-29, 2003.

Estrela, M., Millán, M., Peñarrocha, D., and Pastor, F.: De la Gota Fría al Frente de Retroceso, Centro Francisco Tomás y Valiente, UNED Alzira-Valencia Fundación CEAM, 2002.

Estrela, M., Pastor, F., and Millán, M.: Air Mass Change along Trajectories in the Western Mediterranean Basin in the Torrential Rain Events in the Valencia Region, in: Mediterranean Storms, Proceedings of the 4th EGS Plinius Conference 2002, 2003.

Federico, S., Avolio, E., Bellecci, C., Lavagnini, A., Colacino, M., and Walko, R. L.: Numerical analysis of an intense rainstorm occurred in southern Italy, Nat. Hazards Earth Syst. Sci., 8, 1935, doi:10.5194/nhess-8-19-2008, 2008.

Fita, L., Romero, R., Luque, A., Emanuel, K., and Ramis, C.: Analysis of the environments of seven Mediterranean tropicallike storms using an axisymmetric, nonhydrostatic, cloud resolving model, Nat. Hazards Earth Syst. Sci., 7, 41-56, doi:10.5194/nhess-7-41-2007, 2007.

Kain, J. S. and Fritsch, J. M.: Convective parameterization for mesoscale models: The Kain-Fritsch scheme. The Representation of Cumulus Convection in Numerical Models. Meteoro- 
logical Monographs, No. 46, American Meteorological Society, 165-170, 1993.

Lebeaupin, C., Ducrocq, V., and Giordani, H.: Sensitivity of torrential rain events to the sea surface temperature based on highresolution numerical forecasts, J. Geophys. Res.-Atmos., 111, D12110, 12110-12110, 2006.

Lebeaupin, C., Ducrocq, V., and Giordani, H.: Two-way onedimensional high-resolution airsea coupled modelling applied to Mediterranean heavy rain events, Q. J. Roy. Meteorol. Soc., 135, 187-204, doi:10.1002/qj.338, 2009.

Miglietta, M. M. and Regano, A.: An observational and numerical study of a flash-flood event over south-eastern Italy, Nat. Hazards Earth Syst. Sci., 8, 1417-1430, doi:10.5194/nhess-8-1417-2008, 2008.

Millán, M., Estrela, M. J., and Caselles, V.: Torrential Precipitations on the Spanish East Coast: The role of the Mediterranean Sea Surface Temperature, Atmos. Res., 36, 1-16, 1995.

Millán, M., Estrela, M. J., and Miró, J.: Rainfall Components: Variability and Spatial Distribution in a Mediterranean Area (Valencia Region), J. Climate 18, 2682-2705, 2005.
Molinari, J.: A General Form of Kuo's Cumulus Parameterization, Mon. Weather Rev., 113, 1411-1416, 1985.

Pastor, F., Estrela, M. J., Peñarrocha, D., and Millán, M. M.: Torrential rains on the Spanish Mediterranean coast: Modeling the effects of the sea surface temperature, J. Appl. Meteorol., 40, 1180-1195, 2001.

Pastor, F., Gómez, I., and Estrela, M. J.: Numerical Study of the October 2007 Flash Flood in the Valencia Region (Eastern Spain), Nat. Hazards Earth Syst. Sci., in review, 2010.

Peñarrocha, D., Estrela, M. J., and Millán, M.: Classification of daily rainfall patterns in a Mediterranean area with extreme intensity levels: The Valencia region, Int. J. Climatol., 22, 677695, 2002.

Pielke, R., Cotton, R., Walko, R., Tremback, C., Lyons, W., Grasso, L., Nicholls, M., Moran, M., Wesley, D., Lee, T., and Copeland, J.: A Comprehensive Meteorological Modelling System - RAMS, Meteorol. Atmos. Phys., 49, 69-91, 1992. 